\title{
Transport, Sorption and Desorption of Organic Dye Through Quartz Sand Particles
}

\author{
Amane Jada ${ }^{a, *}$, Rachid Ait Akbour ${ }^{b}$ \\ ${ }^{a}$ Institut de Sciences Des Matériaux De Mulhouse (IS2M-UMR 7361 CNRS - UHA), Mulhouse, France \\ ${ }^{b}$ Laboratoire d'Électrochimie \& Catalyse et Environnement, FSA, Université Ibn Zohr, Agadir, Morocco
}

\begin{abstract}
In this work, the effects of various factors such as the aqueous phase $\mathrm{pH}$, the temperature, the ionic strength, the flow velocity and the electrolyte cation nature on the retention, the mobility and the release of Methylene Blue (MB) through quartz sand (QS), used as porous medium, were investigated. Thus, step-input column experiments were carried out to study the transport, sorption and the desorption mechanisms of the MB molecules through a porous medium made of quartz grains. Hence, the five main parameters related to the adsorption experimental conditions, were varied in order to elucidate the adsorption-desorption mechanisms of MB through the QS medium. The MB adsorbed amount, Qads, was found to decrease by decreasing either the $\mathrm{pH}$, in the range $9.5-4$, or the temperature, in the range $333-293^{\circ} \mathrm{K}$. Similar decrease of $\mathrm{Q}_{\mathrm{ads}}$ was also obtained by increasing the flow rate, $\mathrm{Q}$, in the range $45-90 \mathrm{ml}^{-1}$, or by increasing the affinity of the divalent cation $\left(\mathrm{Ca}^{2+}, \mathrm{Cu}^{2+}, \mathrm{Zn}^{2+}\right.$ and $\left.\mathrm{Ba}^{2+}\right)$ toward the QS surface. However, slight decrease in the MB adsorbed amount, was observed by increasing the ionic strength, in the range $10^{-3}-10^{-1} \mathrm{M}$. The overall data indicate that, electrostatic interaction forces, which occur between the cationic organic pollutant and the negative surface of the quartz substrate, mainly control the adsorption process. In addition, the increase of the adsorbed amount with the temperature, suggests that the adsorption is endothermic in nature.
\end{abstract}

Keywords: Quartz Sand, Methylene Bleu, sorption, desorption, depollution, environment, column experiments

\section{Introduction}

Organic dyes are widely used in textile industries, paper and pulp industries, dye industries, pharmaceutical industries, tannery, and Kraft bleaching industries. Most of these dyes have toxic effects on aquatic life and also on the human's health. Therefore, their release into various aquatic systems, lead to the undesirable environmental pollution. In particular, the discharge of organic dye-containing effluents, such as aromatic compounds, into the water environment is unwelcome, not only because of their color, but also because almost of them and their breakdown products, have toxic, carcinogenic, or mutagenic and teratogenic effects on aquatic life and on human's health [1-3]. Thus, for reasons related to human health and to protect the environment, the removal and/or the separation of the synthetic dyes from aqueous effluents is of great importance. Various methods of dye removal, such as, coagulation [4], electrochemical deposition [5], adsorption on different adsorbents, chemical decomposition by oxidation, photo degradation and microbiological discoloration, were used.

\begin{abstract}
Biological wastewater treatment processes, were found to be ineffective for the removal of dyes [6]. However, the removal of dyes from water by their adsorption on solid supports is one of powerful and low cost treatment processes. In this method, adsorbents such as activated carbon and clays are used. Activated carbon is the most successfully used adsorbent, [711], but the cost limits its use, especially in developing countries. Therefore, there is a need to find an effective and low cost material as an alternative adsorbent for removing the dyes from water. Among the materials that fulfill these requirements, natural adsorbents such as clays and clay minerals [12-15], zeolite [16], agricultural materials [17-19], cellulosic materials, and various industrial wastes have been investigated in various water depollution studies [20]. However, very few studies have focused on the use of quartz sand, as an adsorbent for the removal of dyes from water [21, 22]. The aim of the present work is to study the adsorption of Methylene Blue (MB) from water onto the surface of quartz sand or Fontainebleau sand, which is a inexpensive and abundant adsorbent. The use of quartz sand as adsorbent will allow us to mimic the natural conditions found in hydro systems (soils, aquifers.). In addition, the purpose of this study is to elucidate the mechanism of MB adsorption on the quartz surface, and to investigate the influence
\end{abstract}

* Corresponding author. Tel.: 0033389608709

Fax: 00333 89608799; E-mail: amane.jada@uha.fr

(C) 2018 International Association for Sharing Knowledge and Sustainability

DOI: 10.5383/ijtee.16.02.001 
on the dye retention of various parameters such as the ionic strength, the flow rate, the $\mathrm{pH}$ of the aqueous phase, the temperature, and the nature of the divalent cations present in the aqueous phase.

\section{Material and methods}

\subsection{Porous medium and Dye (Methylene Blue, MB)}

The quartz sand used is Fontainebleau sand purchased from Prolabo (Fig. 1). It contains mainly quartz according to the elementary analysis $(\mathrm{Si}=45.03 \%, \mathrm{O}=52.18 \%, \mathrm{C}<0.3 \%, \mathrm{H}$ $<0.3 \%, \mathrm{Ca}=100 \mathrm{ppm}, \mathrm{Al}=185 \mathrm{ppm}, \mathrm{Mg}<10 \mathrm{ppm}, \mathrm{Na}<50 \mathrm{ppm}$, $\mathrm{Fe}=150 \mathrm{ppm}$ ). The mean grain diameter, $\mathrm{D}_{\mathrm{m}}$, of the sand, is $\mathrm{D}_{\mathrm{m}}$ $=120 \pm 12$ microns, as determined by Scanning Electron Microscopy (SEM) image analysis (Fig. 1), and its isoelectric point IEP $=2.44$, as measured by microelectrophoresis.



Fig. 1. SEM image of natural quartz sand particles. The scale bar at the bottom right is $\mathbf{5 0 0}$ microns.

In addition, the sand's surface area was measured by using Micromeritics ASAP 2000 surface area analyzer. The adsorption-desorption isotherms were obtained by measuring, respectively, the adsorbed and desorbed volumes of $\mathrm{N}_{2}$ at $77 \mathrm{~K}$ and relative pressure $\mathrm{P} / \mathrm{P} 0$ ranging from 0 to 1 . The sample specific surface area is $5.1 \pm 0.1 \mathrm{~m}^{2} \cdot \mathrm{g}^{-1}$, as determined in the relative pressure range $0.05<\mathrm{P} / \mathrm{P}_{0}<0.35$ according to the BET method [23]. It should be noted that in the present work, the quartz sand specific surface area, was also measured in aqueous medium by titration of the negatively charged sand particles by the MB cations. The data gives a specific surface area value of $6.6 \pm 0.1 \mathrm{~m}^{2} \cdot \mathrm{g}^{-1}$, which is $25 \%$ higher than the value found for the quartz sand powder by the BET method.

The dye used is Methylene Blue (MB), supplied from Merck. This basic dye belongs to the class of thiazine dyes. Its chemical formula is $\mathrm{C}_{16} \mathrm{H}_{18} \mathrm{ClN}_{3} \mathrm{~S}$. The $\mathrm{MB}$ dye is used in various chemical industries, such as textile dyeing, biology, pharmacy, and as an antiseptic. The maximum solubility of MB in water, at $20^{\circ} \mathrm{C}$, is equal to $50 \mathrm{~g}$. $\mathrm{L}^{-1}$.

\subsection{Reactants}

All chemical reagents employed in this work are of purity $>99.5 \%$, and the aqueous solutions were prepared using, in all instances, bidistilled water. The ionic strength was fixed by using sodium chloride $(\mathrm{NaCl})$ as salt, (except when indicated). The $\mathrm{pH}$ values of the samples were varied around 4, 6 and 9.5 by buffering the aqueous phase by small amounts of sodium hydroxide $(\mathrm{NaOH})$ or hydrochloric acid $(\mathrm{HCl})$ aqueous solutions. Aqueous solutions of calcium chloride $\left(\mathrm{CaCl}_{2}\right)$, copper chloride $\left(\mathrm{CuCl}_{2}\right)$, zinc chloride $\left(\mathrm{ZnCl}_{2}\right)$ and barium chloride $\left(\mathrm{BaCl}_{2}\right)$, were prepared and used to study the effects of nature of the divalent cations on the transport and deposition of MB in the saturated porous medium of quartz sand.

\subsection{Experimental device}

The experimental device consisted of three components as following and as depicted in Fig. 2:

- A cylindrical column containing the quartz sand made of Altuglas and fitted with a jacket thermostated (length, $\mathrm{L}=10 \mathrm{~cm}$; inner diameter, $\mathrm{D}=1 \mathrm{~cm})$.

- A syringe pumps (Perfusor secura) to control the flow rate.

- A fraction collector, and a pH-meter allowing the continuous measurement of $\mathrm{pH}$ at the column outlet.

The experimental device, held vertically, is fed from bottom to top, in order to facilitate degassing and to reduce the nonuniform flow rise. It should be noted that all the materials used in the experimental device, had demonstrated by preliminary experiments to be none adsorptive toward MB in the conditions used. Experiments were conducted at room temperature, i.e. 20 $\pm 2^{\circ} \mathrm{C}$ except when indicated. In addition, the bottle containing the MB injected solution is made with amber glass to prevent photochemical degradation of the dye molecule, and it was kept under nitrogen atmosphere during all the column experiments.

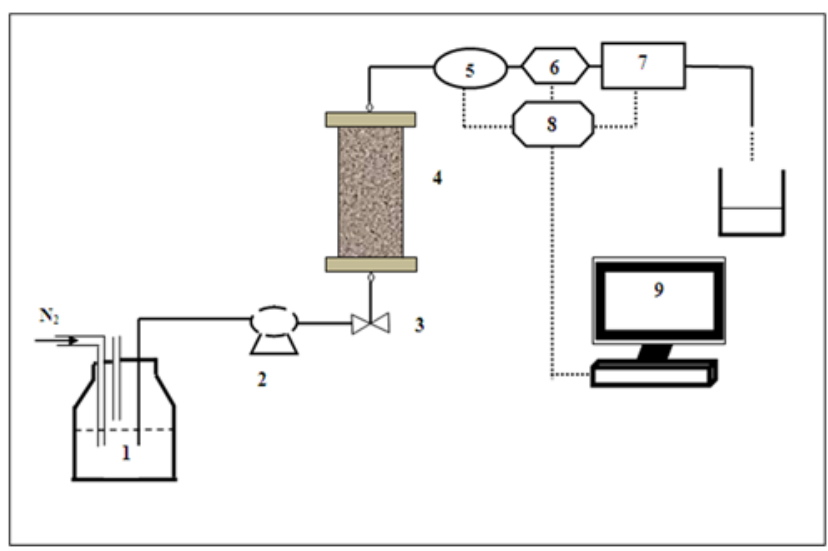

Fig. 2. Experimental setup for column experiments: (1) Solution reservoir containing the electrolyte and the Methylene Bleu (MB) injected solutions; (2) Pumps to deliver the stipulated flow rate; (3) Three way valve; (4) Column made of Altuglas; (5) pH-meter; (6) Conductimeter; (7) An on-line UV-Visible spectrophometer to measure the MB concentration in the effluent; (8) \& (9) A computer to record the breakthrough curves for a conservative solute tracer and MB concentration.

\subsection{Column experiments}

The column pore volume (Vp) and porosity $(\varepsilon)$ were determined by using a Tracer, i.e. Potassium Iodide (KI) at 20 $\mathrm{mg} / \mathrm{L}$. The column outflows for conservative tracer experiments were monitored with a UV-visible spectroscopy at wavelength $\lambda=234 \mathrm{~nm}$. Typical column parameters were: $\mathrm{Vp}=2.29 \mathrm{~mL}$ and $\varepsilon=0.42$, for $9.5 \pm 0.2 \mathrm{~g}$ sand mass.

\subsection{Injecting aqueous solutions through the porous medium}

In the first step, the porous medium is saturated by continuous injection, at constant flow and during one day, of MB free aqueous solution (blank experiments at given $\mathrm{pH}$ and ionic strength, I), until a steady state is reached. Then, in the second step, MB solution is injected continuously, under the same conditions as those made for the blank tests into the column, until equilibrium is reached. In the third step, elution of 
sorbed MB is performed with MB free aqueous phase having the same values of $\mathrm{pH}$ and ionic strength which is different from those previously used in injecting the dye into the porous medium.

\subsection{Collecting and analyzing the column outlet fractions}

The fractions at the outlet of the column were collected at constant volume, and their fluorescence excitation spectra were measured by using a spectrofluorimètre (Shimadzu RF-5001). The fluorescence excitation spectra were recorded at the excitation wavelength range $\lambda_{\text {exc }}=450-720 \mathrm{~nm}$ and emission wavelength, $\lambda_{\mathrm{em}}=750 \mathrm{~nm}$. From the integrated fluorescence intensities of, the outlet or effluent fractions, and the known MB aqueous solutions series (recorded under identical conditions), the MB residual concentrations in the collected fractions, $\mathrm{C}$, were then determined. In the following, only the breakthrough curves dealing with the effect of the ionic strength, I, will be presented. These curves will be expressed as $\mathrm{C} / \mathrm{C}_{0}$ versus $\mathrm{V} / \mathrm{Vp}$. The ratio $\left(\mathrm{C} / \mathrm{C}_{0}\right)$ is the normalized effluent concentration and the (V/VP) is normalized injected solution volume; $\mathrm{C}$ is the total MB concentration measured in each effluent fraction, $\mathrm{V}$ is the cumulated volume eluted since the beginning of the $\mathrm{MB}$ injection, $\mathrm{Vp}$ the pore volume, and $\mathrm{C}_{\mathrm{o}}$ the inlet $\mathrm{MB}$ concentration. From the breakthrough curves, dealing with the effects of various parameters (flow rate, $\mathrm{pH}$, temperature and the nature of divalent cation), we determined the amounts of $\mathrm{MB}$ adsorbed, $\mathrm{Q}_{\mathrm{ads}}$, and the MB desorbed, $\mathrm{Q}_{\mathrm{des}}$, at the quartz sandaqueous solution interface. Note that in all the experiments, each breakthrough curve is composed of two fronts, i.e. an adsorption front followed by a desorption one.

\section{Results and discussions}

\subsection{Effect of the ionic strength}

Figs. 3a and 3b show, respectively, the adsorption and desorption fronts, of the breakthrough curves, dealing with the effect of the ionic strength (I). These figures indicate clearly the influence of ionic strength on the transport, adsorption and desorption of methylene blue (MB) through the quartz sand column. As can be seen in Fig. 3a, they are small differences between the adsorption fronts obtained at various values of the ionic strength. The sorption of MB on the quartz grains in the presence of $\mathrm{NaCl}$ salt can be explained by competition between the $\mathrm{MB}$ and $\mathrm{Na}^{+}$cations, towards the negative sites of the quartz surface ( $\mathrm{pH}>$ IEP), and the zeta potential magnitude, which decreases, as the concentrations of various ionic species, increase at the quartz sand-solution interface. The elution curves as depicted in Fig. 3b show at the beginning the presence of plateaus which are followed, at $\mathrm{V} / \mathrm{Vp}>20$, by diffuse fronts of desorption. The calculated values of the MB amounts sorbed, $Q_{\text {ads, }}$ and released, $Q_{\text {des, }}$ at three values of the ionic strength, I, are presented in Table 1, which shows that Qads decreases slightly when the ionic strength (I), of the solution increases. The sorption of $\mathrm{MB}$ on the quartz grains in the presence of $\mathrm{NaCl}$ salt can be explained by competition between the $\mathrm{MB}$ and $\mathrm{Na}^{+}$ cations, towards the negative sites of the quartz surface $(\mathrm{pH}>$ IEP), and the zeta potential magnitude, which decreases, as the concentrations of various ionic species, increase at the quartz sand solution interface. The MB adsorption on the quartz surface results from the ionic nature of the interaction occurring between the MB cations and the negative surface sites of the quartz sand [24].



Fig. 3a. Effect of the ionic strength, I as fixed by $\mathrm{NaCl}$, on MB adsorption through quartz sand. Initial $\mathrm{MB}$ concentration, $\mathrm{CO}=1$ ppm; $\mathrm{pH}=6$, flow velocity, $\mathrm{Q}=60 \mathrm{ml} / \mathrm{h}$, temperature $\mathrm{T}=293^{\circ} \mathrm{K}$.

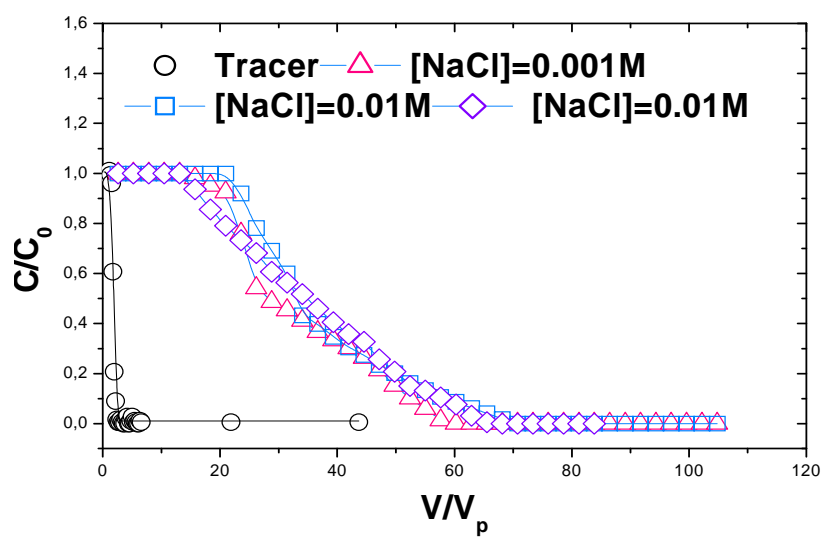

Fig. 3b. Effect of the ionic strength, I as fixed by $\mathrm{NaCl}$, on MB desorption through quartz sand. Initial $\mathrm{MB}$ concentration, $\mathrm{C}_{0}=1$ $\mathrm{ppm} ; \mathrm{pH}=6$, flow velocity, $\mathrm{Q}=60 \mathrm{ml} / \mathrm{h}$, temperature $\mathrm{T}=293^{\circ} \mathrm{K}$.

Table 1. Effect of the ionic strength, I, on the adsorbed, Qads,

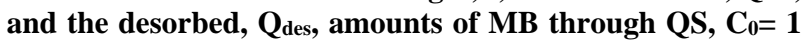
$\mathrm{ppm}, \mathrm{pH}=6, \mathrm{~T}=293^{\circ} \mathrm{K}$, flow rate, $\mathrm{Q}=60 \mathrm{ml} / \mathrm{h}$

\begin{tabular}{ccc}
$\begin{array}{c}\text { Ionic strength, I, } \\
(\mathrm{mol} / \mathrm{L})\end{array}$ & $\begin{array}{c}\mathrm{Q}_{\text {ads }} \\
\left(\mathrm{mg} / \mathrm{m}^{2}\right)\end{array}$ & $\begin{array}{c}\mathbf{Q}_{\text {des }} \\
\left(\mathrm{mg} / \mathrm{m}^{2}\right)\end{array}$ \\
0.001 & 0.125 & 0.015 \\
0.01 & 0.120 & 0.018 \\
0.1 & 0.117 & 0.018 \\
\hline
\end{tabular}

\subsection{Effect of the flow velocity}

The MB adsorbed ( $\left.Q_{\text {ads }}\right)$ and released amounts $\left(Q_{\text {des }}\right)$ at the quartz sand-water interface, and at three different flow velocities values, are presented in Table 2 , and were found to increase both when the flow rate $(\mathrm{Q})$ decreases from $\mathrm{Q}=90 \mathrm{ml} / \mathrm{h}$ to $\mathrm{Q}=45 \mathrm{ml} / \mathrm{h}$. These variations may be due to the decrease, at high flow rate, of the diffusion and the penetration of the MB solute, to the quartz sand surface. Qualitatively, the Peclet number, $\mathrm{Pe}$, which is a relevant parameter in the study of transport phenomena in fluid flows, represents the ratio of two 
time characteristics, one characteristic time corresponding to the transfer by convection and an other one to the transfer by diffusion. The Peclet number, Pe, encompasses in a dimensionless form, the impact of both the flow rate and the particle size, on the MB adsorbed mass on the quartz sand surface [25]. Moreover, it was shown that the collection efficiency $(\eta)$ which is defined for a spherical collector as the ratio between the flow of particles retained by the collector and the incident flux, is related to Pe by a power law having an exponent of $-2 / 3$ or -1 , depending on whether the deposit is limited, respectively, by diffusion (DLD) or by reaction (RLD) [25].

Table 2. Effect of the flow rate, $Q$, on the adsorbed, $Q$ ads, and the desorbed, $Q_{\text {des, }}$ amounts of $\mathrm{MB}$ through $\mathrm{QS}, \mathrm{C}_{0}=1 \mathrm{ppm}$, $\mathrm{pH}=6, \mathrm{~T}=293^{\circ} \mathrm{K}$, ionic strength, $\mathrm{I}=10^{-3} \mathrm{M}(\mathrm{NaCl})$.

\begin{tabular}{ccr}
$\begin{array}{c}\text { Flow rate, } \mathbf{Q}, \\
(\mathrm{ml} / \mathrm{h})\end{array}$ & $\begin{array}{c}\mathrm{Q}_{\text {ads }} \\
\left(\mathrm{mg} / \mathrm{m}^{2}\right)\end{array}$ & $\begin{array}{r}\mathrm{Q}_{\text {des }} \\
\left(\mathrm{mg} / \mathrm{m}^{2}\right)\end{array}$ \\
45 & 0.166 & 0.020 \\
60 & 0.116 & 0.016 \\
90 & 0.076 & 0.016 \\
\hline
\end{tabular}

Thus, according to these power laws, the fraction of MB retained on the quartz surface decreases when the flow rate, $Q$, increases. Our experimental data are in a good agreement with the theoretical predictions using the colloidal approach. Our results agree also with the data reported by others [26]. According to these authors, the increase in the flow rate (Q) disadvantages the acidic dye adsorption on montmorillonite. Our findings are consistent with the work reported by [16], showing that the adsorption of hexadecyl trimethyl ammonium bromide on zeolites, depends on the flow rate. The effect of flow rate on the retention of $\mathrm{MB}$, results from the duration time when the fluid is in contact with the quartz surface (contact time). Thus, when the flow rate is low, the number of adsorbed MB cations on the solid surface is higher, as resulting from the long contact time occurring between the fluid molecules and the quartz surface.

\subsection{Effect of the aqueous phase $\mathrm{pH}$}

The adsorption experiments of MB on the quartz sand surface is carried out at three values of the aqueous phase $\mathrm{pH}$ of 4, 6 and 9.5. As listed in Table 3, both $Q_{\text {ads }}$ and $Q_{\text {des }}$ were found to increase with the increase of the aqueous phase $\mathrm{pH}$.

Table 3. Effect of the aqueous phase $\mathrm{pH}$, on the adsorbed, $Q_{\text {ads, }}$ and the desorbed, $Q_{\text {des, }}$ amounts of $\mathrm{MB}$ through $\mathrm{QS}$, $\mathrm{C}_{0}=1 \mathrm{ppm}, \mathrm{T}=293^{\circ} \mathrm{K}$, ionic strength, $\mathrm{I}=10^{-3} \mathrm{M}(\mathrm{NaCl})$, flow rate $=60 \mathrm{ml} / \mathrm{h}$.

\begin{tabular}{ccc}
$\mathrm{pH}$ & $\begin{array}{c}\mathrm{Q}_{\text {ads }} \\
\left(\mathrm{mg} / \mathrm{m}^{2}\right)\end{array}$ & $\begin{array}{c}\mathbf{Q}_{\text {des }} \\
\left(\mathrm{mg} / \mathbf{m}^{2}\right)\end{array}$ \\
4 & 0.104 & 0.016 \\
6 & 0.116 & 0.016 \\
9.5 & 0.240 & 0.048 \\
\hline
\end{tabular}

The observed increases of Qads and Qdes with the increase of the aqueous phase $\mathrm{pH}$ shown in Table 3 indicate that the $\mathrm{pH}$ is a parameter that strongly affects the adsorbed MB amount. The influence of the aqueous phase $\mathrm{pH}$ on the variation of the MB sorbed amount, results in the bonding forces involved in the formation of the MB-silica complex. Such bonding interactions include electrostatic, as well as Van der Waals forces [27]. Others authors [28], have reported similar $\mathrm{pH}$ effect, on the adsorption of dye molecules, at mineral-water interface. According to these authors, the dye adsorption capacity on silicates increases with increasing the $\mathrm{pH}$ of the aqueous phase. Moreover, it has been found recently, [29] that the adsorption of basic dye from aqueous solution onto clay surface, reached its maximum value in basic medium (i.e., at $\mathrm{pH}=10$ ).

\subsection{Effect of temperature}

The influence of the temperature on the transport of the MB basic dye through the porous medium was investigated and the adsorbed Qads; and desorbed, Qdes, MB amounts were calculated from the obtained breakthrough curves. The data are presented in Table 4 and indicate that an increase in the temperature from $293^{\circ} \mathrm{K}$ to $333^{\circ} \mathrm{K}$ leads to an increase in Qads from 0.12 to $0.17 \mathrm{mg} / \mathrm{m}^{2}$, i.e. an increase of about $42 \%$. However, as can be shown in Table 4, the same increase in temperature does not show significant change of $Q_{\text {des. }}$

Table 4. Effect of the temperature, $T$, on the adsorbed, Qads, and the desorbed, $Q_{\text {des, }}$ amounts of $M B$ through $\mathrm{QS}, \mathrm{C}_{0}=1$ ppm, $\mathbf{p H}=6$, ionic strength, $\mathrm{I}=10^{-3} \mathrm{M}(\mathrm{NaCl})$, flow rate, $\mathrm{Q}=$ $60 \mathrm{ml} / \mathrm{h}$.

\begin{tabular}{|c|c|c|}
\hline $\begin{array}{c}\text { Temperature, } T \text {, } \\
\left({ }^{\circ} \mathbf{K}\right)\end{array}$ & $\begin{array}{c}Q_{\text {ads }} \\
\left(\mathbf{m g} / \mathrm{m}^{2}\right)\end{array}$ & $\begin{array}{c}Q_{\text {des }} \\
\left(\mathbf{m g} / \mathbf{m}^{2}\right)\end{array}$ \\
\hline 293 & 0.124 & 0.016 \\
\hline 313 & 0.150 & 0.020 \\
\hline 333 & 0.166 & 0.016 \\
\hline
\end{tabular}

Such dye behaviour proves that the adsorption of MB at the quartz sand aqueous solution interface is an endothermic process. The same thermal behaviour was observed by others authors [14], when they studied the adsorption of MB on kaolinite. In additions, others authors [12], examined the retention of methyl violet onto perlite, and they found that the rate of methyl violet adsorption increased with increasing temperature and $\mathrm{pH}$ of the aqueous phase. The data in table 4 can be explained by the fact that an increase of the temperature leads to an increase of thermal agitation, and also to an increase of the diffusion rate of the ions, resulting in an enhancement of the exchange, and/or displacement, of $\mathrm{Na}^{+}$ions, immobilized near the surface solid, by MB cations. Finally, the adsorption of MB on the quartz sand particles involves two main steps: A first transport step, during which the MB molecules diffuse from the aqueous phase to the quartz surface, and a second step (anchoring or binding step) in which the MB molecules adsorb on the solid surface. The kinetics of transport and binding of MB molecules at solid liquid interface, are controlled by different factors, such as ionic strength, $\mathrm{pH}$ of the aqueous phase, and the temperature of the medium.

\subsection{Effect of the nature of divalent cations present in the aqueous phase}

In this experiment series, we examined the effect of divalent metal ions on the MB adsorption from water onto quartz sand. The divalent cations used, were in the form of metal chloride salts $\left(\mathrm{CaCl}_{2}, \mathrm{CuCl}_{2}, \mathrm{ZnCl}_{2}\right.$ and $\left.\mathrm{BaCl}_{2}\right)$, at a concentration of $10^{-3} \mathrm{M}$. The Qads and Qdes were calculated from the mass balances of the breakthrough data, and their variations with the divalent cation nature, are presented in Fig. 4. The results show that the MB adsorbed mass, Qads, decreases 
in the sequence: $\mathrm{Cu}^{2+}>\mathrm{Zn}^{2}+>\mathrm{Ca}^{2+}>\mathrm{Ba}^{2+}$. This behaviour may be explained by the cation affinity toward the solid support. Thus, the saturation of the quartz sand by the divalent cations $\left(\mathrm{Me}^{2+}=\mathrm{Ca}^{2+}, \mathrm{Cu}^{2+}, \mathrm{Zn}^{2+}\right.$ and $\left.\mathrm{Ba}^{2+}\right)$ reduce the number of the solid negative sites, resulting in reduction of the electrostatic attraction between the MB cations and the solid surface. However, the decrease in the electrostatic attraction between the MB cations, and the solid surface depends on the ionic radius, $\mathrm{r}_{\mathrm{i}}$, of the divalent cation, $\mathrm{Me}^{2+}$, present in the aqueous solution. Thus, according to Coulomb's law, the divalent cation, $\mathrm{Me}^{2+}$, having the largest ionic radius, ri, (non-hydrated radius), is preferentially adsorbed on the solid surface [30]. The ionic radii of different divalent cations $\mathrm{Me}^{2+}$, decrease in the following sequence:

$$
\mathrm{Ba}^{2+}\left(\mathrm{r}_{\mathrm{i}}=140 \mathrm{pm}\right)>\mathrm{Ca}^{2+}\left(\mathrm{r}_{\mathrm{i}}=100 \mathrm{ppm}\right)>\mathrm{Zn}^{2+}\left(\mathrm{r}_{\mathrm{i}}=74\right.
$$



ppm) $>\mathrm{Cu}^{2+}\left(\mathrm{r}_{\mathrm{i}}=73 \mathrm{ppm}\right)$

Fig. 4a. Effect of the divalent cation nature $\mathrm{Me}^{2+}$, on $\mathrm{MB}$ adsorption through quartz sand. Initial $\mathrm{MB}$ concentration, $\mathrm{C}_{0}=1 \mathrm{ppm} ; \mathrm{pH}=6$, flow velocity, $Q=60 \mathrm{ml} / \mathrm{h}$, temperature $T=293^{\circ} \mathrm{K}$., $\left[\mathrm{Me}^{2+}\right]=10^{-3} \mathrm{M}$, $\mathrm{Me}=\mathrm{Ba} ; \mathrm{Ca} ; \mathrm{Zn}$ and $\mathrm{Cu}$.



Fig. 4b. Effect of the divalent cation nature $\mathrm{Me}^{2+}$, on $\mathrm{MB}$ desorption through quartz sand. Initial $\mathrm{MB}$ concentration, $\mathrm{C}_{0}=1 \mathrm{ppm} ; \mathrm{pH}=6$, flow velocity, $Q=60 \mathrm{ml} / \mathrm{h}$, temperature $T=293^{\circ} \mathrm{K}$., $\left[\mathrm{Me}^{2+}\right]=10^{-3} \mathrm{M}$, $\mathrm{Me}=\mathrm{Ba}$; $\mathrm{Ca}$; $\mathrm{Zn}$ and $\mathrm{Cu}$.

Therefore, the strong adsorptions of MB cations on the quartz sand, as observed in the presence of $\mathrm{Cu}^{2+}$ and $\mathrm{Zn}^{2+}$ ions, result from the slight reduction of the quartz negative surface charge and/or the low affinities of the metal cations toward the solid. On the other hand, the low adsorptions of MB cations on quartz particles, in the presence of $\mathrm{Ca}^{2+}$ and $\mathrm{Ba}^{2+}$ ions, are due to the strong reduction of the quartz negative surface charge and/or to the higher affinities of the metal cations toward the solid.

\section{Conclusion}

A natural quartz sand column was used to study the transport, retention, and release of Methylene Blue (MB). The quartz sand was selected as adsorbent, due to its availability and low cost. The data presented in this work show the effects of various parameters, such as ionic strength, flow rate, $\mathrm{pH}$ of the aqueous phase, the temperature of the medium, and the nature of the divalent cation, on the transport and the retention of MB dye, through the porous medium. The main results are summarized as follows:

- The retained MB amount, in the quartz sand porous medium, decreases significantly when the flow rate increases. However, a slight decrease in the retained MB amount occurs when the ionic strength of the aqueous phase increases;

- The fraction of MB deposited on the quartz increases by increasing either the temperature of the medium, or by raising the $\mathrm{pH}$ of the aqueous phase;

- The presence of metal divalent cations in the medium decreases in all instances, the adsorbed MB amount. However, such decrease depends on both, the metal cation affinity toward the solid surface, and its hydration by water molecules;

- The adsorption of MB on the quartz sand particles is endothermic nature and it is irreversible.

The overall data provide useful information to elucidate the mechanisms of complex formation, occurring in soil and groundwater, between inorganic or organic cations and the quartz sand surface.

\section{Nomenclature}

Ionic strength, $\mathrm{mol} / \mathrm{L}(\mathrm{M})$

$\mathrm{T}$ Temperature of the column, ${ }^{\circ} \mathrm{K}$

Q Flow rate, $\mathrm{ml} / \mathrm{h}$

Qads Adsorbed amount of Methylene Bleu, mg $/ \mathrm{m}^{2}$

Qdes Desorbed amount of Methylene Bleu, $\mathrm{mg} / \mathrm{m}^{2}$

D Inner column diameter, $\mathrm{cm}$

L Column length, $\mathrm{cm}$

$\mathrm{D}_{\mathrm{m}} \quad$ Mean grain diameter, micron

$\mathrm{C}_{0} \quad$ Inlet $\mathrm{MB}$ concentration, $\mathrm{ppm}$

C Outlet MB concentration, ppm

$\mathrm{pH} \quad$ Aqueous phase $\mathrm{pH}$

$\mathrm{P} \quad$ Applied pressure

Po Environmental/Atmospheric pressure

Greek Symbols

$\begin{array}{ll}\lambda_{\text {exc }} & \text { Excitation wavelength, } \mathrm{nm} \\ \lambda_{\mathrm{em}} & \text { Emission wavelength, } \mathrm{nm}\end{array}$

$\varepsilon \quad$ Porosity 


\section{Acknowledgments}

This work was done in the frame of the project: Sustainable Treatment Processes of Effluents for Reuse of Water in Agriculture (SETPROpER European ERANET MED Water13_043; 2016-2019, FP7, Horizon 2020), and the supports of the funding agencies of France: National Research Agency (ANR) and the CNRST-Maroc, are gratefully acknowledged.

\section{References}

[1] McKay G., M.S. Otterburn, D.A. Aga, Fullers earth and Fired clay as adsorbent for dye stuff, equilibrium and rate constants, Water Air Soil Pollut, 1985. 24: p 307-322.

https://doi.org/10.1007/BF00161790

[2] Gregory A.R., S. Elliot, and P. Khuge, Ames testing of direct black 38 parallel carcinogenecity, J. Appl Toxicol, 1981. 1: p. 308-313.

https://doi.org /10.1002/jat.2550010608

[3] Liakou S., S. Pavlou, and G. Lyberatos, Ozonation of azo dyes, Water Sci. Technol, 1997. 35: p. 279-286.

https://doi.org/10.1016/S0273-1223(97)00036-X

[4] Vandevivere P.C., R. Bianchi, and W. Verstraete, Treatment and reuse of wastewater from the textile wet-processing industry: Review of emerging technologies. Journal of Chemical Technology and Biotechnology, 1998. 72: p. 289-302.

https://doi: 10.1002/(SICI)1097-4660(199808)72:4

[5] Martinez-Huitle C.A., and E. Brillas, Decontamination of wastewaters containing synthetic organic dyes by electrochemical methods, A general review. Applied Catalysis B-Environmental, 2009. 87: p. 105-145.

https://doi: 10.1016/j.apcatb.2008.09.017

[6] Walker G.M., and L.R. Weatherley, Adsorption of acid dyes onto granular activated carbon in fixed beds. Water Res, 1997. 31: p. 2093-2101.

https://doi.org/10.1016/S0043-1354(97)00039-0

[7] Jia-Ming C., and W. Chia-Yuan, Desorption of dye from activated carbon beds: effects of temperature, pH, and alcohol. Water Res, 2001. 35: p. 4159-4165.

https://doi.org/10.1016/S0043-1354(01)00127-0

[8] Yang X.Y., and B. Al-Duri, Application of branched pore diffusion model in the adsorption of reactive dyes on activated carbon, Chem Eng J, 2001. 83: p. 15-23.

https://doi.org/10.1016/S1385-8947(00)00233-3

[9] Kannan N., and M.M. Sundaram, Kinetics and mechanism of removal of methylene blue by adsorption on various carbons-a comparative study, J. Dyes Pig, 2001. 51: p. 25-40.

https://doi.org/10.1016/S0143-7208(01)00056-0

[10] Karaca S., A. Gürses, M. Açikyildiz, and M. Ejder, Adsorption of cationic dye from aqueous solutions by activated carbon, Microporous and Mesoporous Materials, 2008. 115: p. 376-382. https://doi.org/10.1016/.j.micromeso.2008.02.008

[11] Walker G.M., and L.R. Weatherley, Fixed bed adsorption of acid dyes onto activated carbon. Environ Pollution, 1998. 99: p. 133-136.

https://doi.org/10.1016/S0269-7491(97)00166-8

[12] Dogan M. and M. Alkan, Adsorption kinetics of methyl violet onto perlite, Chemosphere, 2003. 50: p. 517-528.

https://doi.org/10.1016/S0045-6535(02)00629-X

[13] Ho Y.S., and C.C. Chiang, Sorption studies of acid dye by mixed sorbents, Adsorption-Journal of the International Adsorption Society, 2001. 7: p. 139-147. https://doi.org/10.1023/A:1011652224816

[14] Ghosh D. and K.G. Bhattacharyya, Adsorption of methylene blue on kaolinite, Appl. Clay. Sci, 2002. 20: p. 295-300.

https://doi.org/10.1016/S0169-1317(01)00081-3

[15] Rytwo G., D. Tropp, and C. Serban, Adsorption of diquat, paraquat and methyl green on sepiolite: experimental results and model calculations, Appl. Clay Sci, 2002. 20: p. 273-282.

https://doi.org/ 10.1016/S0169-1317(01)00068-0

[16] Benkli Y.E., M.F. Can, M. Turan, and M.S. Celik, Modification of organo-Zeolite surface for the removal of reactive azo dyes in fixed-bed reactors, Water Research, 2005. 39: p. 487-493.

https://doi.org/10.1016/j.watres.2004.10.008

[17] McKay G., M. El Geundi, and M.M. Nassar, External mass transport processes during the adsorption of dyes onto bagasse pith, Water Res, 1988. 22: p. 15271533.

https://doi.org/10.1016/0043-1354(88)90165-0

[18] Robinson T., B. Chandran, and P. Nigam, Removal of dyes from an artificial textile dye effluent by two agricultural waste residues, corncob and barley husk, Environ. Int, 2002. 28, p. 29-33.

https://doi.org/10.1016/S0160-4120(01)00131-3

[19] Annadurai G., R.S. Juang, and D.J. Lee, Use of cellulose based wastes for adsorption of dyes from aqueous solutions, J. Hazard. Mater, 2002. B 92: p. 263-274.

https://doi.org/10.1016/S0304-3894(02)00017-1

[20] Wang C.C., L.C. Juang, T.C. Hsu, C.K. Lee, J.F. Lee, and F.C. Huang, Adsorption of Basic Dyes onto Montmorillonite, J. Colloid Interface Sci, 2004. 273: p. 80-86.

https://doi.org/10.1016/j.jcis.2003.12.028

[21] Espantaleón A.G., J.A. Nieto, M. Fernández, A. Marsal, Use of activated clays in the removal of dyes, Appl. Clay Sci, 2003. 24: p. 105-110.

https://doi.org: 10.1016/S0169-1317(03)00153-4

[22] Al-Asheh S., F. Banat, and L. Abu-Aitah, The removal of methylene blue dye from aqueous solutions using activated and non-activated bentonites, Adsorpt Sci Technol, 2003. 21: p. 451-462. 
https://doi.org/10.1260/026361703769645780

[23] Brunauer S., P.H. Emmett, and E. Teller, Adsorption of gases in multimotecular layers, J. Am. Chem. Soc, 1938. 60: p. 309-319.

https://doi.org/10.1021/ja01269a023

[24] Jada A., Ait Akbour R., Douch J, Surface charge and adsorption from water onto quartz sand of humic acid, Chemosphere, 2006. 64: p. 1287-1295.

https://doi.org/10.1016/j.chemosphere.2005.12.063

[25] Rousseau D., L. Hadi, and L. Nabzar, Injectivity Decline From Produced-Water Reinjection: New Insights on In-Depth Particle-Deposition Mechanisms. SPE PRODUCTION \& OPERATIONS, 2008. 23: n4, p. 525-531.

[26] Lin S.H., R.S. Juang, and Y.H. Wang, Adsorption of acid dye from water onto pristine and acid-actived clays in fixed beds. Journal of Hazardous Materials, 2004. B 113 : p. 195-200. https://doi.org/10.1016/j.jhazmat.2004.06.028

[27] Kaouna F., A. Gaid, and H. Ait Amar, Cinétique d'adsorption du bleu méthylène sur différents types d'argiles kaolinitiques. Bull. Soc. Chim. Fr 1987. 4: p. 581-587.

[28] Kar H.S., G.L. Mundhara, G.L. Sharma, and J.S. Tiwari, Sorption-desorption studies of cationic dyes on silica gel pretreated with alkalis in relation to chromatography. Colloids Surf, 1991. 55: p. 23-40.

https://doi.org/10.1016/0166-6622(91)80080-8

[29] Tsai W.T., Y.M. Chang, C.W. Lai, C.C. Lo, Adsorption of basic dyes in aqueous solution by clay adsorbent from regenerated bleaching earth, Applied Clay Sci, 2005. 29: p. 149-154.

https://doi.org/10.1016/j.clay.2004.10.004

[30] Alloway, B.J., Heavy metals in soils, Alloway B.J. (ed.), (Dir), London Blackie Academic and Professional, 1995. 